\title{
Out-of-hospital Cardiac Arrest as a Reportable Disease in Norway
}

Ingvild B.M. Tjelmeland ${ }^{1}$, Jo Kramer-Johansen ${ }^{1,2}$, Kristine Mydske-Earl1

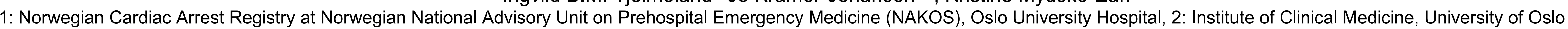

\section{Purpose}

To describe the effect on the Norwegian Cardiac Arrest Registry (NorCAR), when out-of-hospital cardiac arrest (OHCA) was made a reportable disease.

\section{Background}

OHCA is a time critical event, and survival after OHCA is an internationally accepted measure of overall EMS quality. OHCA registries monitor and provide feedback to the EMS providers, but fulfill their purpose only if they collect highquality, validated data and incidences that reflects the real burden of OHCA in the society.

Norway has a population of $\sim 5.2$ millions. Since 2013 reporting data to NorCAR has been mandatory. Coverage in NorCAR is defined as the percentage of the Norwegian population served by the reporting EMS. We also present population-based incidence and survival rates.

\section{Regional variations}

The reported incidence of cardiac arrest varies from $<40$ to $>90$ cases per 100000 inhabitants. The expected incidence of cardiac arrest in each region is the national average with a lower and upper limit due to common-cause variation based on regional population. Variation limits of $+/-3$ SD resulted in only 4 out of 18 health trusts reporting high or low incidence rates in 2017.

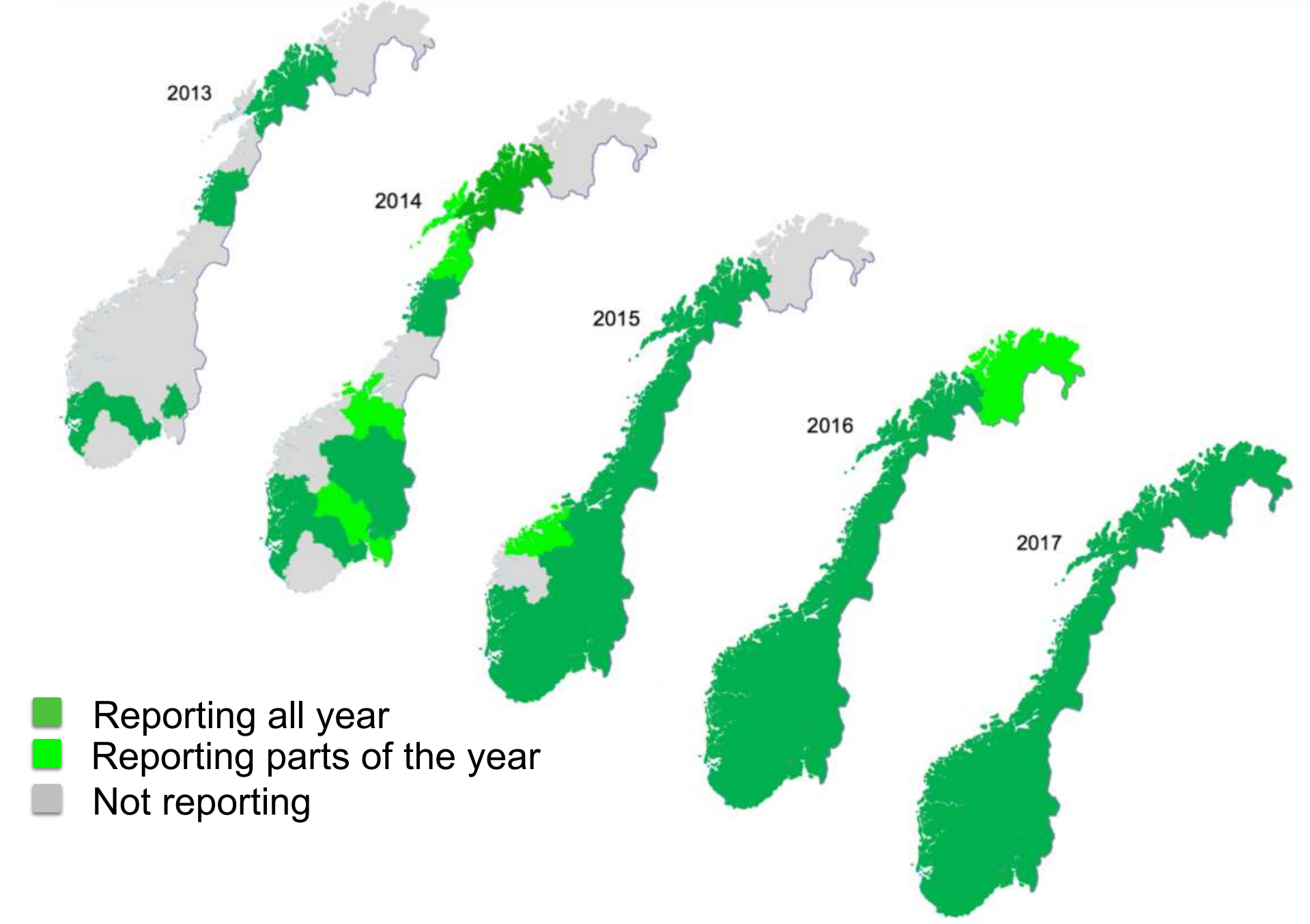

Figure 1. Health trusts reporting to NorCar from 2013 to 2017

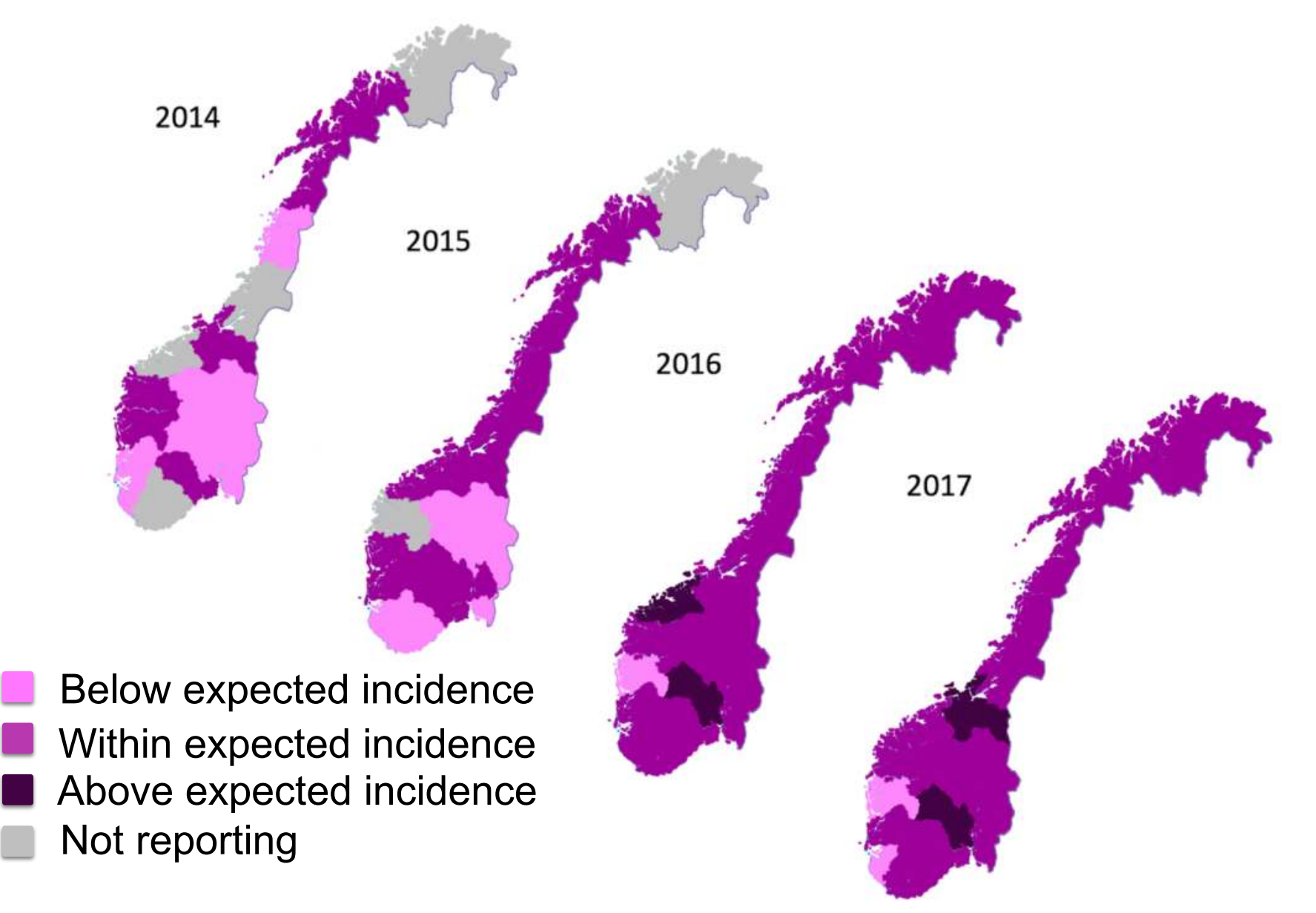

Figure 2. Variation in incidence of CA reported to NorCar based on commoncause variation limits of $+/-3 S D$.

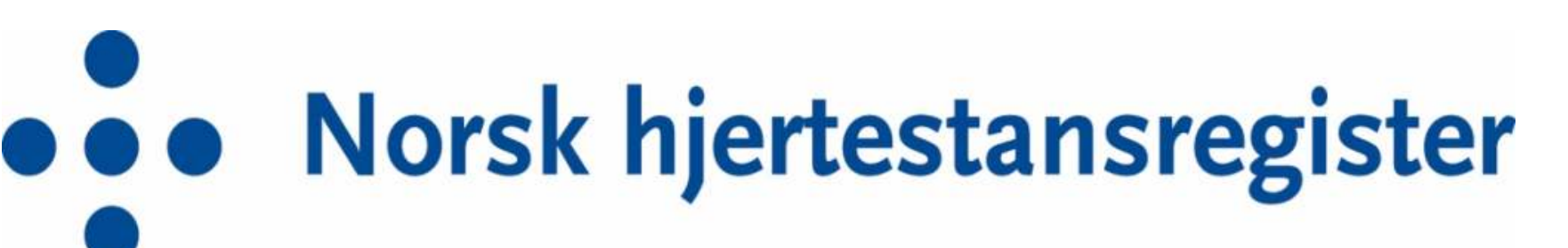

\section{Results}

Out of the 18 EMS health trusts in Norway, the number reporting to NorCAR increased from $8(44 \%)$ in 2013. By 2016 all EMS health trust were reporting.

The reported incidence of CA increased from 44 (2013) to 60 (2017) per 100000 personyears. Reported 30-day survival rates from all-cause OHCA was 7.7 (2013), 5.9 (2014), 7.3 (2015), 7.1 (2016) and 7.0 (2017) per 100000 person-years.

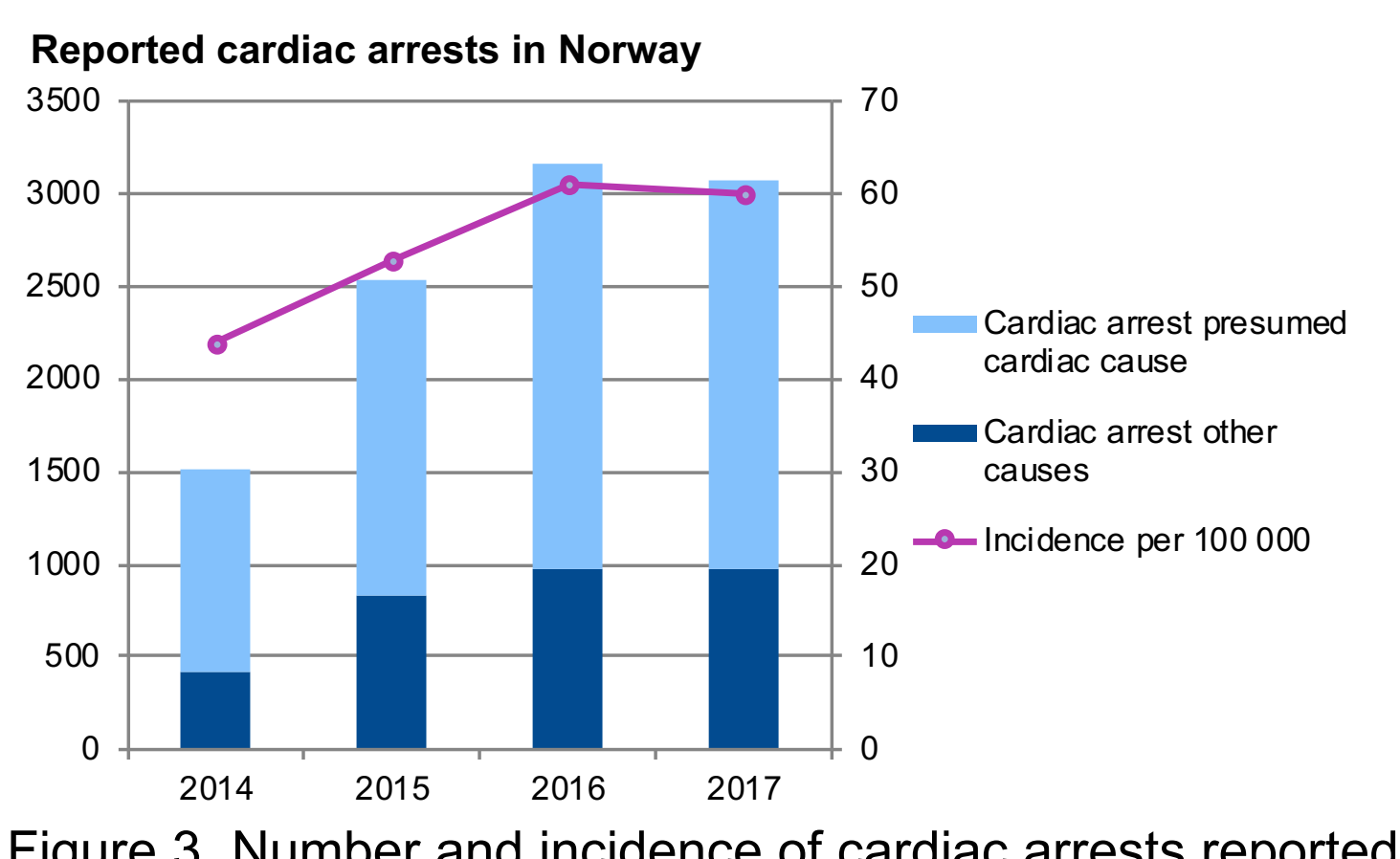

Figure 3. Number and incidence of cardiac arrests reported to NorCAR (presumed cardiac and non-cardiac cause)

\section{Conclusion}

Our experience suggests that mandatory reporting is valuable when creating a population-based registry. In addition to this, close follow-up of local data managers and feedback to the EMS services probably have contributed to the high coverage and data quality in our registry. 